
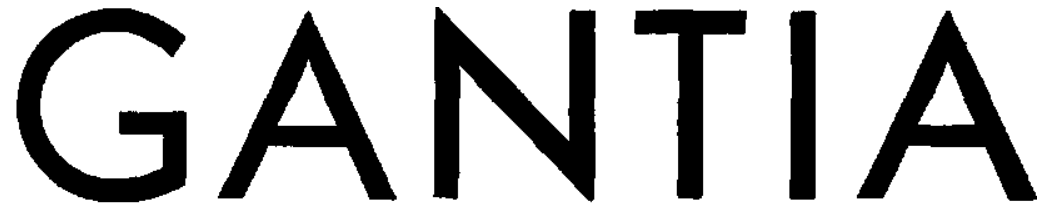

Boletim Técnico do Instituto Agronômico do Estado de São Paulo

Vol. 16

Campinas, novembro de 1957

N. ${ }^{0} 15$

\title{
O FARELO DE TORTA DE MAMONA NA ADUBAÇÃO DA BATATINHA (*)
}

\author{
O. J. Boock \\ Engenheiro-agrônomo, Dr. Agr., Seçāo de Raízes e Tubérculos, \\ Instituto Agronômico
}

\section{R E S U M O}

Na composiçăo de formulas de adubação para a cultura da batatinha com freqüência entrava o farelo de torta de algodão, com resultados satisfatórios (1). Fm consequêência da proibição do seu emprêgo como fertilizante, para ser usado exclusivamente na composição de raçōes para animais, procurou-se um outro farelo que pudesse substituí-1o e que não tivesse emprêgo "in natura", na alimentaçāo animal. Dentre êles sobressaiu-se o farelo de torta de mamona, que possui um princípio tóxico, a ricinina.

No presente trabalho são fornecidos os resultados da sua utilização na composição de fórmulas de ađubação para batatinha. As conclusões a que se chegou vieram recomendar 0 seu uso em confronto com o farelo de torta de algodão e sulfato de amônio. Os resultados alcançados, em experiências levadas a efeito em seis localidades do Estado e em épocas diferentes, mostraram que a mistura dêsse fertilizante com o sulfato de potássio e superfosfato, ou outro adubo nitrogenado, em partes iguais, pode substituir o farelo de torta de algodão

\section{1 - INTRODUÇÃO}

$\mathrm{Na}$ impossibilidade de empregar o farelo de torta de algodão na composição de fórmulas para a adubação da batatinha, Solanum tuberosum L. (1), visto o seu uso estar restrito à alimentação de animais, procurou-se conseguir-lhe um sucedâneo, e o mais indicado na ocasião foi o farelo de torta de mamona.

Idênticamente ao constatado com o farelo de torta de algodão, é o de mamona pobre em nitrogênio, fósforo e potássio, conforme a análise dada a seguir:

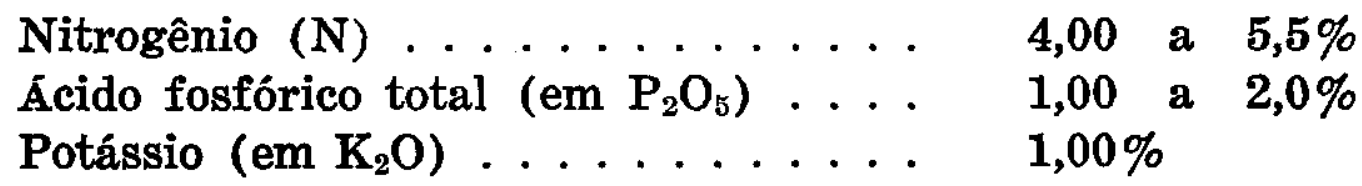


2.3 - A partir de 1952, em três localidades do Estado de São Paulo - Campinas, Limeira e São José dos Campos - iniciou-se nova série de experiências (Projeto 53) onde não só se comparou o efeito do farelo de torta de mamona em relação ao de algodão, como também sôbre as variedades de batatinha "Eigenheimer" e "Konsuragis".

O delineamento usado foi o de blocos ao acaso, seis tratamentos (2 variedades $\times 3$ fórmulas de adubação) e quatro repetições.

Os tratamentos foram os seguintes:

a) Eigenheimer

1 - Superfosfato + sulfato de potássio + sulfato de amônio

2 - superfosfato + sulfato de potássio + torta de algodão

3 - superfosfato + sulfato de potássio + torta de mamona

b) Konsuragis

1 - superfosfato + sulfato de potássio + sulfato de amônio

2 - superfosfato + sulfato de potássio + torta de algodão

3 - superfosfato + sulfato de potássio + torta de mamona

Nas localidades de Campinas e Limeira, procedemos a dois plantios, um no chamado período "da sêca", fevereiro-junho, e outro no "das águas", setembro-fevereiro; em São José dos Campos, com irrigação e durante dois anos seguidos, apenas no mês de abril, por ser ali essa uma das épocas mais indicadas.

As análises dos solos das três localidades revelaram o seguinte: Campinas - terreno argilo-silicoso, pardacento, ácido $(\mathrm{pH}=4,90)$, teor médio de matéria orgânica e nitrogênio total e baixo em fósforo e potássio; Limeira - terreno argilo-silicoso pardacento, ácido ( $\mathrm{pH}=4,95)$, teores altos de matéria orgânica e nitrogênio total, médio em fósforo e muito pobre em potássio; São José dos Campos - terreno argilo-silicoso, escuro, acidez média $(\mathrm{pH}=5,80)$ teores altos de matéria orgânica e nitrogênio total, fósforo e potássio, teores médios.

Por ocasião dos protocolos de vegetação ficou evidenciado que as tortas não causaram nenhum acréscimo no número de falhas (Quadro 1), observando-se, apenas, em São José dos Campos, um retardamento no nascimento das plantas dos lotes que receberam tortas, e um número maior de falhas devido ùnicamente ao ataque de lagarta rosca. $O$ desenvolvimento vegetativo pouca diferença mostrou entre os vários tratamentos, havendo em alguns casos ligeira superioridade dos lotes que receberam torta, como ocorreu no plantio "da sêca" em Limeira. 
As produções sofreram variações, algumas vêzes acentuadas, de acôrdo com a localidade e época de plantio. Assim, em Campinas, variou na época "da sêca" entre 6, 7 e 7,7 toneladas por hectare, o que era de se esperar por ter sido feito em época sêca e sem irrigação, enquanto "nas águas" já se elevou entre 10,7 a 17,7 toneladas. Na plantação "da sêca" a "Konsuragis" suplantou a "Eigenheimer" e na "das águas" se deu o contrário. Em Limeira (2) a influência benéfica das tortas em relação ao sulfato de amônio se fêz sentir nìtidamente, no período sêco, o que não se notava no período "das águas", o mesmo se dando com as variedades, isto é, a "Konsuragis" se comportou melhor do que a "Eigenheimer" na falta de chuvas. Êste fato vem esclarecer a dúvida por nós levantada (1) quando dissemos: "A terceira experiência em Mococa foi plantada em maio e colhida em agôsto, portanto em época pouco chuvosa no Estado de São Paulo. Por êsse motivo, e por não contarmos com irrigação, as produções desta última experiência foram mais baixas, parecendo-nos pelos resultados, que o farelo de torta de algodão não é aconselhado como adubo para o plantio da batata nessa época, principalmente quando usado como fonte única de nitrogênio."

Em São José dos Campos, apenas uma plantação decorreu normalmente, pois a segunda foi prejudicada por ataque de lagarta rosca e crestamento fitóftora. Os dados contidos no quadro 1 revelam as diferenças existentes.

Pela análise estatística dos resultados conclui-se o que é dado a seguir:

Campinas - Na plantação "da sêca" não houve diferenças nem entre variedades, nem entre adubações (C.V. = 8,8\%). Nas "águas" a "Eigenheimer" suplantou a "Konsuragis", sendo que sòmente nesta última variedade houve diferenças entre os adubos, isto é, a aplicação de tortas motivou maior produção do que a de sulfato de amônio. As tortas não se diferençaram quanto à produção (C.V. = $9 \%)$.

Limeira - Na plantação "da sêca", ambas as variedades reagiram melhor à adubação com tortas. Entre estas não houve diferenças significativas, o mesmo podendo se dizer entre as variedades (C.V. = 32,7\%). Nas "águas" a "Eigenheimer" foi superior à "Konsuragis". Entre adubações não houve diferenças (C.V. = $9,7 \%)$.

São José dos Campos (1) : — Cultura não irrigada: a "Eigenheimer" demonstrou ser, sob as condições da experiência, significativamente superior à "Konsuragis"; entre adubações não houve diferenças (C.V. $=20,8 \%$ ). Cultura irrigada: a variedade "Konsuragis" foi ligeiramente superior à "Eigenheimer"; o sulfato de amônio determinou aumento na produção em relação às tortas de algodão e mamona; entre estas não houve diferenças (C.V. $=10 \%$ ). 


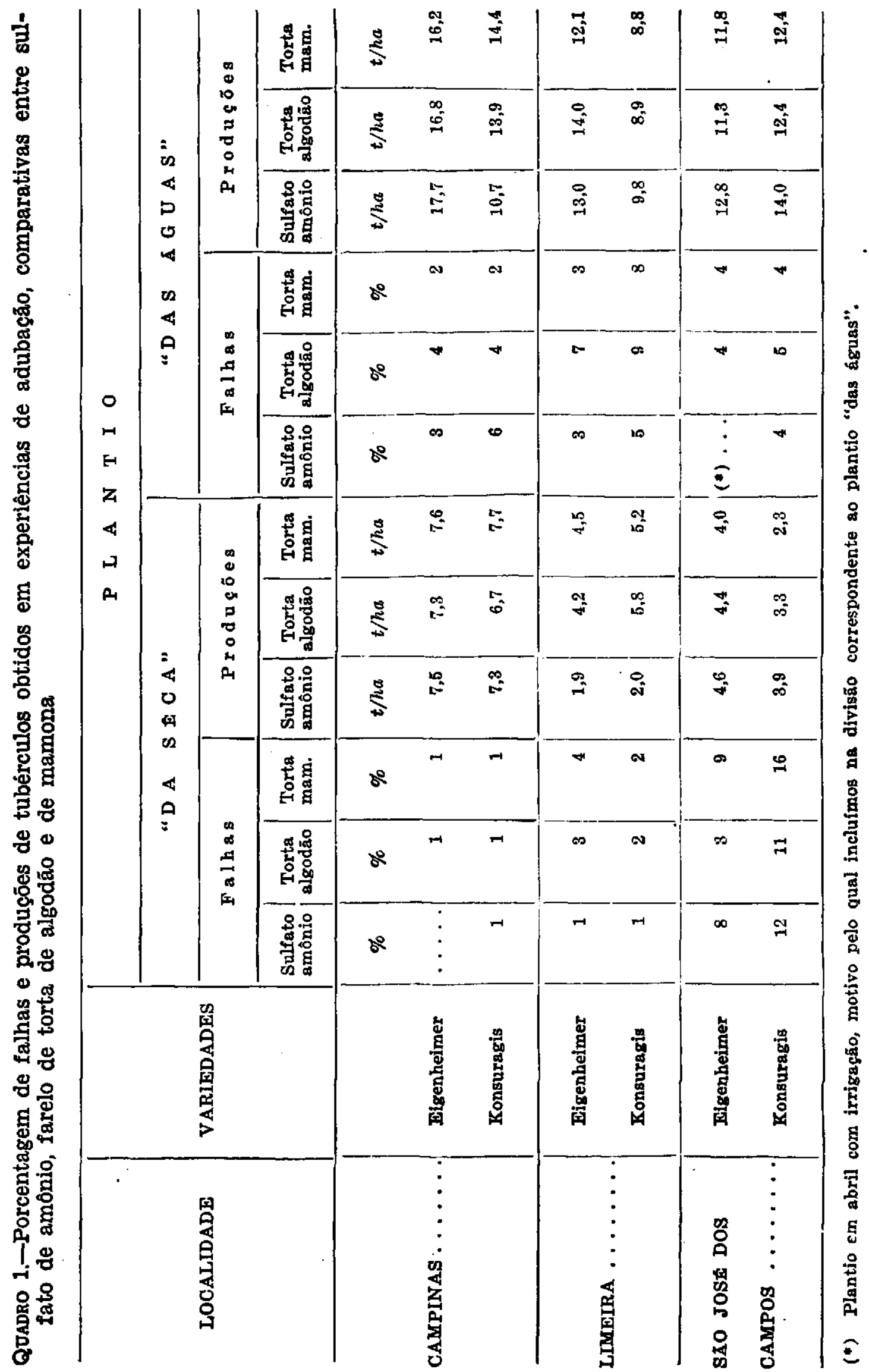


A classificação dos tubérculos colhidos nas experiências demonstrou o seguinte:

a) em Campinas, na época sêca, não se notaram diferenças sensíveis entre variedades e tratamentos, ao passo que na época chuvosa a "Eigenheimer" apresentou porcentagens mais elevadas de tubérculos graúdos, principalmente quando recebeu farelo de torta de algodão ou de mamona ;

b) em Limeira, já os resultados obtidos foram bem esclarecedores; assim, na época sêca, os lotes adubados com tortas deram tubérculos de maior pêso médio enquanto que, com sulfato de amônio, não chegamos a obter batatinhas acima de 80 gramas; na segunda plantação as porcentagens mais elevadas de graúdos foram dadas pela "Eigenheimer", notando-se ainda uma influência nítida das tortas sôbre o aumento do pêso médio dos tubérculos;

c) em São José dos Campos, em cultura não irrigada, a "Konsuragis" suplantou nìtidamente a "Eigenheimer" quanto à maior porcentagem de batatinhas graúdas, não se notando, todavia, influência dos adubos nesse párticular; na cultura irrigada idêntico fato foi observado, entre variedades, quanto à produção total, porém, a "Konsuragis" reagiu melhor às tortas do que a "Eigenheimer".

Examinando os tubérculos a fim de verificar possíveis danos causados pela ação dos adubos, nada se constatou de anormal (2).

\section{3 - CONCLUSÕES}

Dos resultados obtidos em experiências levadas a efeito em seis localidades do Estado de São Paulo, Sorocaba, Itapecerica, Santo André, Campinas, Limeira e São José dos Campos, chega-se à conclusão de que o farelo de torta de mamona poderá ser empregado na composição de fórmulas de adubação para a batatinha, de preferência em mistura com adubos nitrogenados minerais, pois não só concorre para o aumento de produção de tubérculos como eleva a porcentagem de tubérculos comerciáveis.

\section{THE CASTOR SEED MEAL AS A FERTILIZER IN IRISH POTATO CROP}

\section{S U M M A R $\mathbf{Y}$}

Fertilizer experiments with Irish potato under field conditions were carried out at six different localities of the State of Sāo Paulo, and showed that the use of the castor seed meal along with superphosphate and potassium sulfate, affords identical results in tuber yield as those obtained with either cotton seed meal or ammonium sulfate, as a source of nitrogen.

\section{LITERATURA CITADA}

1. BOOCK, O. J. O farelo de torta de algodão na adubação da batatinha. Bragantia 10:[329]-333. 1950.

2. \& IORDELO, L. G. E. Diplópoda depredador de tubérculos de batatinha. Bragantia 12:[343]-347. 1952.

3. CAstro, J. B. e KIEHL J. Trabalhos da Seção de Raízes e Tubérculos do Instituto Agronômico, realizados em 1936-1938. [Não publicados]

(1) Para a execuçăo desta experiência tivemos como colaborador o Eng ${ }^{\circ}$ Agr ${ }^{\circ}$ Antonio G. Gomes. 